\title{
ESTUDO COMPARATIVO SOBRE A PERCEPÇÃO DA INCLUSÃO ESCOLAR
}

\author{
Talita Aparecida Costa Alvarenga ${ }^{1}$ \\ Faculdade Presbiteriana Gammon. \\ Marcel Aêgon Silva \\ Faculdade Presbiteriana Gammon. \\ Rafaella Cristina Campos ${ }^{3}$ \\ Faculdade Presbiteriana Gammon. \\ Leandro Veloso Silva ${ }^{4}$ \\ Faculdade Presbiteriana Gammon.
}

\section{RESUMO}

O objetivo do presente trabalho é comparar a percepção da inclusão escolar em uma escola pública e em uma escola privada, ambas localizadas na cidade de Lavras/MG. A natureza da pesquisa é qualitativa, que consiste na busca pela compreensão do fenômeno, de forma descritiva e argumentativa sem levantamento de hipóteses ou relações causais. O mecanismo para coleta de dados foi um questionário semiaberto para 16 professores e 04 membros do departamento administrativo das escolas e uma dinâmica no Ensino Fundamental - Anos Finais, de uma turma de 60 Ano, em ambas as escolas. Como resultado, obteve-se uma demonstração positiva em relação à rede privada e negativa na rede pública, devido à falta de informação e interesse.

Palavras-chave: Inclusão escolar, Percepção, Educação.

\footnotetext{
${ }^{1}$ Graduanda em Educação Física-Licenciatura da Faculdade Presbiteriana Gammon-FAGAMMON. E-mail: talitacalvarenga@hotmail.com

${ }^{2}$ Graduando em Educação Física-Licenciatura da Faculdade Presbiteriana Gammon-FAGAMMON. E-mail: aegon99a@hotmail.com

${ }^{3}$ Professora orientadora da Faculdade Presbiteriana Gammon-FAGAMMON. Email: rafaella_ccampos@ hotmail.com

${ }^{4}$ Professor orientador da Faculdade Presbiteriana Gammon-FAGAMMON. E-mail: leandro.vellozo@yahoo.com.br
} 


\section{COMPARATIVE STUDY ON THE PERCEPTION OF SCHOOL INCLUSION}

\section{ABSTRACT}

The objective of the present work is to compare the perception of school inclusion in a public school and in a private school, both located in the city of Lavras / MG. The nature of the research is qualitative, which consists of seeking to understand the phenomenon, in a descriptive and argumentative manner without raising hypotheses or causal relationships. The data collection mechanism was a semi-open questionnaire for 16 teachers and 4 members of the schools' administrative department and a dynamic in elementary school II, from a 6th grade class, in both schools. As a result, there was a positive demonstration in relation to the private network and a negative one in the public network, due to the lack of information and interest.

Keywords: School Inclusion. Perception. Education.

\section{Introdução}

\section{Contextualização temática}

Incluir é promover convivência e compartilhamento de experiências entre pessoas com características diferentes, sendo estas diferenças físicas, emocionais e/ou mentais - cognitivas. Recomenda-se que a inclusão aconteça nas diversas esferas sociais, tais como trabalho, escola e lazer, não só para adaptar socialmente o indivíduo incluído, mas também para propiciar a este sua integração e independência, possibilitando com que suas ações façam parte operante do grupo em que está inserido, e não somente desempenhando um papel passivo (MANTOAN, 2015).

O caminho entre a inclusão e a exclusão é tênue. Se a inclusão não for efetivada nas práticas, e nas relações, esta é feita parcialmente, e, portanto, de forma ineficaz. A co-dependência que a inclusão tem das relações humanas é que a faz uma ação crítica, com características por vezes intangíveis e com forte indício histórico de perpetuação do subjulgamento das diferenças, faz com o debate seja por vezes infrutífero, efêmero e arraigado de perspectivas egóicas, e não coletivas (SILVA, 2009).

O contexto da inclusão escolar é instigante e desafiador, isso porque a escola consiste no primeiro espaço socialmente designado para que os primeiros desafios sociais e intelectuais sejam lançados ao indivíduo. É na escola que os limites e diferenças pessoais são colocados em evidência, na colisão da busca individual e coletiva por pertencimento grupal e aceitação pessoal.

Se for levada em conta a diversidade física, emocional, comportamental e cognitiva que todos os indivíduos de uma escola têm, entre professores, funcionários e alunos, é difícil destacar um padrão de congruência em que possa ser chamado de maioria. Talvez seja pelos movimentos antagônicos de busca de quebra de padrões, em contradição com a dificuldade histórica de desvincular a imagem europeia de pessoa branca e família nuclear como norma, que a inclusão ainda esteja no patamar de imposição governamental nas escolas, estando marginalizada nos esforços das relações humanas cotidianas.

Uma sociedade inclusiva reconhece e valoriza a diversidade, buscando a quebra de pequenos grupos chamados minorias, em busca de formação de grupos maiores e heterogêneos. A partir 
desse princípio, e tendo como base o cenário ético dos direitos humanos, destaca-se a necessidade de garantir a inclusão de todos, com equidade e acessibilidade (MANTOAN, 2004).

A inclusão escolar pressupõe, conceitualmente, uma educação apropriada e de qualidade dada juntamente com todos os alunos, onde deve ser criado um trabalho pedagógico que favoreça a todos os alunos, sem exceções. Ou seja, em um contexto de inclusão escolar, as diferenças são as regras de manifestação de uma turma de alunos, sendo assim, nenhum tipo de característica que seja mais protuberante ao grupo deve ser encarada como limitadora, mas sim como desafiadora, e, dentro das condições e aparato educacional, estas diferenças que os alunos manifestam demandam apoio personalizado (AGUIAR e DUARTE, 2005).

Estudos brasileiros mostram que, faltam posturas básicas para a garantia não apenas do acesso físico, que é o vetor mais evidente na busca por inclusão, mas falta também, continuidade na busca do sucesso social, vivencial, cognitivo e emocional desses alunos com alguma necessidade especiais matriculados em classes comuns (MENDES, 2006).

Nota-se com a contextualização acima que há dificuldade de compreender o que é uma demanda inclusiva nas escolas, uma vez que esta compreensão ainda é focada em pessoas com deficiência física, com solução eficaz estritamente no aparato físico da escola - corrimão, rampas etc. marginalizando assim as demandas inclusivas de alunos com dificuldade cognitiva e emocional, tornando então, o processo inclusivo frágil.

Além disso, dada evidência de que as relações humanas é um fator vital para que a inclusão de fato ocorra, nota-se que incluir é muito mais que um processo, é uma interação. Sendo assim, questiona-se:

\section{Problemática}

No contexto escolar, seja ele de uma escola pública ou particular, como é percebida a inclusão escolar?

\section{Objetivo principal}

Comparar a percepção da inclusão escolar em uma escola pública e em uma escola privada, ambas localizadas na cidade de Lavras/MG.

\section{Objetivos específicos}

Definem-se dois objetivos específicos:

Primeiro, identificar, a partir da ótica dos professores, quais são as demandas para inclusão escolar, comparando o contexto de uma escola pública e de uma escola privada localizadas na cidade de Lavras/MG.

Segundo, averiguar, a partir da ótica dos alunos, as ações e características que para eles são fatores de inclusão ou exclusão em um grupo, comparando o contexto de uma escola pública e de uma escola privada localizadas na cidade de Lavras/MG.

Terceiro, compreender, a partir da gestão da escola, quais são as ações e estratégias utilizadas e exigidas para promover a inclusão escolar, comparando o contexto de uma escola pública e de uma escola privada localizadas na cidade de Lavras/MG.

\section{Justificativa}

Justifica-se a execução deste trabalho pela sua contribuição teórico-prática. Os educadores brasileiros têm o desafio de buscar por uma educação para todos, respeitando as diferenças, compreendendo os direitos de cidadão, eliminando estereótipos, promovendo equidade e além de 
tudo isso, buscando sempre por métodos de ensino-aprendizagem coerentes com o público, e capazes de, afetivamente, se relacionar com os alunos (RUIZ, 2008).

A profissão docente é uma profissão de relações humanas, que demanda empatia, sendo assim, em um contexto de inclusão, este exercício, que deveria ser orgânico e dinâmico, por vezes se torna penoso e mais segregador do que agregador. Com relação à inclusão no Brasil, estamos seguindo devagar. Mesmo com a promulgação da Lei da LDB (Lei de Diretrizes e Bases da Educação Nacional, 9.394/96, já imaginava, no artigo 96, que os sistemas de ensino deveriam certificar, aos alunos com necessidades especiais: currículo, métodos, recursos e organização, específicos para atender suas necessidades; e no artigo 37, que a educação básica devia fornecer "oportunidades educacionais apropriadas, consideradas as características do alunado, seus interesses, condições de vida e de trabalho", o que legalizava a necessidade da escola se transformar para esse novo cenário (ROSIN-PINOLA; DEL PRETTE, 2014). A preparação de corpo docente está longe de ser adequada para as diversas demandas explicitamente inclusivas que chegam cotidianamente nas escolas.

\section{Referencial teórico}

\section{Descrição da coleta do material bibliográfico}

Para a construção da discussão de material bibliográfico deste trabalho, opta-se pelo levantamento de artigos científicos completos publicados na base de indexação SCIELO (Scientific Eletronic Library Online). Define-se que o período de publicação dos artigos compreende os anos de 2006 a 2016, garantindo assim, atualidade do debate a ser construído compreendendo o gap de uma década de publicações nacionais, para que a realidade brasileira seja pautada.

Para triar, os artigos completos, inicialmente utilizou-se para buscar a expressão chave "inclusão and escolar". O resultado foi de 250 artigos completos encontrados, já com filtro de ano de publicação, área - ciências humanas e ciências da saúde - e idioma - estritamente português - aplicados.

Sendo este um número muito expressivo para a construção de um trabalho, delimitou-se então a seleção dos artigos por tema expresso no resumo dos trabalhos. Buscaram-se artigos para compor três vertentes de discussão propostas pelos autores, sendo estas perspectivas: primeiro, a inclusão escolar na perspectiva do aluno - selecionando de 02 artigos em 250; segundo, a inclusão escolar na perspectiva do professor - selecionando 10 artigos em 250; e terceiro, a inclusão na perspectiva nacional brasileira e seu impacto nas diretrizes escolares selecionando 07 em 250.

Além desta seleção por leitura de resumo, notou-se duplicata de indicação de artigos, sendo estes, excluídos na construção deste trabalho, bem como trabalhos que contemplavam espaços a quem da escola básica, como por exemplo, empresas, ensino superior e escolas especiais. Foram excluídos também trabalhos que tratavam de inclusão de pessoas de alto desempenho, como superdotados, isso porque os autores pensam que este irá traçar um novo escopo de pesquisa que pode e deve ser contemplado em nova oportunidade de pesquisa.

Desta forma, o total de artigos selecionados para compor a discussão teórica deste trabalho é de 19 artigos completos. Nota-se com as delimitações de temas na busca dos artigos que há menos artigos publicados na ótica dos maiores interessados na inclusão escolar: os alunos e os professores. O maior volume de publicação de artigos é focado na análise da lei de amparo da inclusão 
escolar originária da Constituição, mas não há na mesma proporção publicações que abarque os participantes ativos e cotidianos do contexto da escola.

Após definir criteriosamente a seleção de material bibliográfico, segue abaixo os eixos temáticos e as discussões acerca destes temas.

\section{A inclusão escolar na perspectiva do aluno}

Nesta circunstância, o aluno com deficiência exerce obrigações e finalidades relevantes no grupo, contribuindo para o progresso da concepção de pertencimento ao grupo, essencial para a vivência de constatar se englobado. $O$ entendimento das concepções do aluno com deficiência proporciona ao educador atribuir se mais adequadamente as dificuldades de seus alunos, da mesma maneira acrescentar o entendimento de pertencimento nas aulas de educação física. A inclusão deste aluno é vinculada aos padrões das relações sócias oferecidas, onde elas precisam se benéficos e aceitar que ele se note recebido, respeitado por sua competência de executar um dever relevante no grupo. Deste modo, a pesquisa da inclusão de alunos com deficiência deve ter como eixo principal as expectativas e concepções do próprio aluno com deficiência, possibilitando o entendimento dos aspectos otimistas e pessimistas neste método. De modo global a vivência de estar englobado requer o melhoramento da organização escolar. Esta organização deve trazer a estruturação de um entendimento de harmonia entre membros da escola (ALVES; DUARTE, 2014).

Deste modo, é fundamental que realizações de pesquisas analisando a inclusão e as vantagens da aula de educação física, da mesma maneira o conhecimento do aluno com deficiência a respeito da qualidade de vida. Com o propósito primordial buscar entender as concepções do aluno com deficiência sobre as aulas de educação física. Em junção nos benefícios na qualidade de vida por meio da educação física escolar, todos os alunos foram favoráveis as aulas. Os pontos essenciais citados foram integração social, desenvolvimento físico e psicológico.

Deste modo, conforme o conceito dos alunos com deficiência, benefícios significativos em sua qualidade de vida são visíveis nas aulas de educação física escolar inclusiva. Portanto, é essencial que os educadores continuem se qualificando de modo que possa receber estes alunos cada vez com mais qualidade (NACIF; et al, 2016).

\section{A Inclusão escolar na perspectiva do professor}

A educação inclusiva surge no contexto político indicando alterações drásticas no meio escolar. Enfim, com base na Lei de Diretrizes e Bases da Educação Nacional - LDBN - n. 9.394/96, todas as crianças, livremente com suas situações de desenvolvimento, têm o direito de apoio pedagógico social preferencialmente em salas de aulas regulares (MENDONÇA; SILVA, 2015).

Portanto, é essencial que os educadores retifiquem sua forma de educar, tente possibilidades que consigam beneficiar o método de ensino aprendizagem de todas as crianças que apresentam deficiência. De maneira a ficar a favor do acaso. Deste modo o progresso de meios, maneiras, técnicas usadas em sala de aula precisam conceder na pratica a perspectiva de realização e originalidade de pessoas que mostram qualquer deficiência de aprendizagem. Dessa forma constata se que é que no sistema da vida social, de convívio num mundo educacional com outros sociais que na criança vão mostrando os métodos psicológicos e humanos. E é a com base desse ponto que inicia a estabelecer e produzir a individualidade do sujeito que permitirão conectar se com o social, já que este estabelece seu ambiente de prática (BIAVATTI, 2012). 
No universo atual, unido, sem limites, conectado por rede de referência, penso que um dos ensinamentos principais da educação nos métodos inclusivos e afirmar direitos, ingresso, conquista e manutenção de todos os(as) alunos(as) com deficiências na educação regular (COSTA, 2010).

A inclusão escolar, na ótica da educação inclusiva, necessita da atuação e do empenho de distintos responsáveis educacionais. Quando as condutas desses responsáveis são favoráveis e interdependentes no universo escolar, crescem as possibilidades de conhecimento, além de serem retidos e multiplicados com o tempo. A inclusão escolar, no entendimento da educação inclusiva, busca consequentemente a atuação e o comprometimento de diversos fatores educacionais. No momento em que os procedimentos desses motivadores são pertinentes e autônomos no universo escolar, ampliam se as capacidades de conhecimento, que mais adiante podem ser sustentados e descobertos com o tempo.

Ao acrescer possibilidades umas às outras, podem ocasionar em costumes culturais que permanecem ao longo do tempo. Padrões tais como, a conduta dos educadores da educação especial, que efetua a moldagem da tarefa para o aluno, a conduta do educador em sala de aula, que educa o aluno a ler. Ao construir o material de aprendizagem, a conduta dos diretores na presença das políticas educacionais atuais, a conduta dos pais de supervisionar os aprendizados dos filhos e várias condutas prometedoras, que indicam a preparação dos alunos. (BENITEZ; DOMENICANI, 2015).

A gestão de formatos inerentes, em relação à inclusão escolar de educandos com necessidades especiais, as seriações trocam tantos os aspectos particulares individuais (princípios, intuitos, disputas e dúvidas) como os aspectos particulares sociais (conceitos e sistematização figurada da escola), contudo, ainda, muito pouco se pesquisou aquilo que, de verdade, os responsáveis humanos comprometidos, adiante os responsáveis da educação, efetivamente sentem quando passa a formar parte do cotidiano escolar de um educando insólito em correlação aos outros, em virtude de seus déficits intelectuais, corporal e sensitivo, e que sentidos rodeiam seus comportamentos diante a esse novo educando (GOMES; REY, 2007).

Exatamente a ponderação a essa idealização que está no apoio do sentido inclusivo, o desempenho ligado de pessoas que convivem distintivamente o alcance ao entendimento precisaria afetar o coletivo, gerando novas vivências curriculares, tornando menos rígido a grade de disciplinas e a organização de grupos, afinal, formando novas medidas no meio escolar e nas ligações educativas como um todo. A educação especial deixaria de existir como esfera específica modificando se em apoio educacional especializado, que executa como alicerce ao trabalho da sala de aula e as ligações gerais da escola (ANJOS; ANDRADE; PEREIRA, 2009).

Lamentavelmente em grande parte das escolas não encontramos uma educação uniforme para todos. Uns procuram, mas nem sempre atingem devido aos enormes obstáculos encontrados como, arquitetura, falta de profissionais específicos, ligação com a família e, especialmente, o prejulgamento (REIS, 2001).

Entendeu se que o educando ali introduzido solicitava, muitas vezes, itens, cuidado e até mesmo organização de ensino apropriada as suas necessidades. Dependendo da deficiência, o educando depara com obstáculos e não consegue proceder às funções oferecidas pelo educador, e frequentemente não chegam a associar o padrão dos outros educandos. É essencial não apenas a interrupção de exemplos já presentes, mas propiciar o apreço as diversidades. É essencial que todos colaborem do modo considerável para esse método, mesmo na presença das incertezas que afligem a maior parte da comunidade escolar que receberam ou estão próximo a obter um deficiente com necessidades especiais (RESENDE, 2010). 
O entendimento do roteiro de inserção da política é de essencial relevância para que se consiga seguir no caminho do que esse título instrui com informações que baseiam intentos e que produzam incitações a serem arremetidos pelo poder público e por todos que se importam em transformar nossas escolas em cenários educacionais inclusivos (MANTOAN, 2015).

\section{A inclusão na perspectiva nacional brasileira e seu impacto nas diretrizes escolares}

Como discutir sobre inclusão sem tocar em seu lado negativo? Comumente conversa-se mais sobre exclusão do que inclusão, esse conhecimento parece mostrar-se de modo mais acentuado em nossa sociedade. $\mathrm{O}$ assunto inclusão/exclusão é bastante argumentado, nas áreas sociais, econômicas e políticas. Tem pessoas que excluem, e do outro há os excluídos, em suma, uma prática opressiva entre essas duas posições: quem controlará e quem vai fazer parte ou não dos incluídos (KIBRIT, 2013).

Posteriormente, as escolas brasileiras têm tido uma resistente ação em prol da amplificação do acesso e democratização do ensino. Essa atividade, chamada de inclusão escolar, é produto de argumentações anteriores que tem argumentos importantes de pessoas com necessidades especiais relaciona-se com os demais alunos da escola. Uma referência histórica dessa mudança foi a Declaração de Salamanca (1994) que conduziu, como essenciais diretrizes para o levantamento de uma escola inclusiva, que tem com alguns princípios: Toda criança e adolescente tem permissão à educação e deve ter a chance de chegar e manter o nível apropriado de aprendizagem. Toda criança e adolescente possuem características únicas, ou seja, tem habilidades e necessidades diferentes. Os meios educacionais devem ser reestruturados e os projetos educacionais deveriam ser preparados no sentido de cogitar a variedade de tais características e necessidades. Os alunos com necessidades especiais precisam ter acesso à escola regular, ela deve acolhê-los em uma pedagogia centralizada na criança. As escolas regulares que têm inserida uma orientação inclusiva compõem os meios mais eficientes de lutar contra comportamentos discriminatórios, gerando grupos acolhedores e assim conseguir uma educação para todos (ROSIN-PINOLA; DEL PRETTE, 2014).

A criação de uma visão educacional inclusiva, onde o foco é a mudança das instituições escolares em lugares para receber aos alunos com distintas condições de vida e necessidades educacionais, protesta o empenho efetivo da administração pública, para que tenham políticas que sejam capazes de acabar com a estrutura excludente da escola. Nessa situação, matriculam os alunos com necessidades especiais, que na realidade brasileira, têm assegurado seu direito à educação, fazendo a matricula no ensino comum e no serviço educacional especializado, por meio das conquistas consolidadas na Lei de Diretrizes e Bases da Educação Nacional, LDB N 9394/96. $\mathrm{O}$ apoio educacional especializado, feito nas salas de recursos multifuncionais, transformou-se na expressão mais representativa da educação inclusiva na escola pública brasileira (SANTOS; MARTÍNEZ, 2016).

Quando se pensa e fala sobre inclusão, vai além das necessidades e deficiências para vencera realidade da exclusão que atualmente está sendo imposta no nosso meio, na qual os estudantes são inseridos nas escolas pela rejeição do acesso ao saber sistematizado, à continuidade na escola e à saída com a habilidade de uma sabedoria que lhes ajude o real exercício da cidadania (SANTOS; MARTÍNEZ, 2016).

O crescimento das ideias inclusivas, assim como a junção da sociedade a elas, prosseguiu incrivelmente por conta do auxílio ao reconhecimento dos direitos da pessoa com deficiência, consequência dos confrontos de diferentes áreas da sociedade. Nas últimas duas décadas, a preservação dos direitos das pessoas com necessidades especiais tem preenchido espaço progressivo no debate e na política, com realce no ano de 2009 , em que a aprovação da Convenção sobre os Direitos das Pessoas com Deficiência criou uma variedade de novas práticas e auxiliou a redimensionar as já existentes (LAPLANE, 2014). 
As conversar sobre a inclusão surgem aí, na maior parte, mantendo a sua criação funcionalista e salientando a defesa de condições para intervir sobre o ambiente, com a finalidade de que cada um possa executar sobre si mesmo (PAGNI, 2015).

O ambiente escolar é o segundo mediador entre o aluno e o ambiente. É na escola que o conhecer culturalmente ordenado e historicamente erguido é propagado de forma mais sistemática. Além do mais, é nesse meio que os alunos irão conhecer novas proporções de interação, comportamentos e serão exibidos a novos valores, tendo mérito fundamental na socialização infantil, no desenvolvimento e na aprendizagem (MATURANA; CIA, 2015).

\title{
Caminhos metodológicos
}

\author{
Natureza da Pesquisa
}

O objetivo principal deste artigo é comparar a percepção da inclusão escolar em uma escola pública e em uma escola privada, ambas localizadas na cidade de Lavras/MG.

Para tanto, opta-se pela metodologia qualitativa de pesquisa, que consiste na busca pela compreensão do fenômeno, de forma descritiva e argumentativa sem levantamento de hipóteses ou relações causais; a metodologia qualitativa prevê que o objeto estudado, seja ele qual for, tem manifestação autônoma e nuances peculiares ao olhar de cada pesquisador e de cada circunstância (RAMPAZZO, 2005).

Partindo da metodologia qualitativa, define-se o método de estudo de caso. 0 estudo de caso consiste na investigação de uma situação específica, que permite a observância do objeto de pesquisa, possibilitando dentro da especificidade, a compreensão do fenômeno que é manifesto em outras dimensões e situações. O estudo de caso não necessariamente demanda generalização, mas se for intencional, isto pode ser feito (RAMPAZZO, 2005).

Tendo definido a metodologia como qualitativa e o método como estudo de caso, faz-se necessária a descrição do local e sujeitos da pesquisa que segue abaixo.

\section{Local e Sujeitos da Pesquisa}

Para participar da construção deste trabalho, foram abordadas duas escolas, sendo uma pública e uma privada, ambas localizadas na cidade de Lavras/MG Define-se o lócus como a cidade de Lavras/MG dada sua historicidade e concentração de escolas. A cidade é conhecida como a 'Cidade dos Ipês e das Escolas', tendo em todo o seu território (64) escolas públicas e (22) escolas privadas, de acordo com o site www.escolas.inf.br, com demanda de matriculados crescente, dada a localização de Lavras que é uma cidade satélite, ou seja, na sua região há muitas outras cidades que dependem desta para realizar suas atividades de subsistência e formação, tais como trabalho e estudo. Há também concentração de instituições de ensino superior, o que corrobora que a cidade é, para a região, centralizadora na oferta de ensino em qualquer instância, sendo então, relevante para estudos da área de educação.

Para a realização deste trabalho foram selecionadas uma escola pública e uma escola privada, ambas ofertam o ensino fundamental II que foi o seguimento avaliado para o estudo.

Definindo então que duas escolas de vertentes distintas farão parte do estudo, este então é de cunho comparativo. Ou seja, este estudo irá sobrepor duas realidades, abordando uma mesma temática que é a inclusão escolar. $O$ estudo comparativo visa identificar e compreender as diferenças e similaridades do fenômeno estudado em mais de um contexto, traçando 
um paralelo bem como uma fusão entre os achados da pesquisa. Não visa polarizar, mas sim, interpor (BULGACOV, 1998).

Como respondentes da pesquisa foram abordados professores, alunos e responsáveis técnicos de cada segmento educacional. Os critérios de inclusão para respondentes da pesquisa são: se professor ou técnico administrativo da escola, que deve estar na mesma a pelo menos um ano, para que seja possível dizer do tema abordado na realidade específica da escola. Se aluno deve ser consentido pela escola a sua participação, e devem estar regularmente matriculados na mesma. Os técnicos administrativos a qual são referidos neste trabalho, devem ser, estritamente, pessoas ligadas à gestão da escola, como direção geral e departamental. Idade, tempo de matriculado ou contratado e gênero não são levados em conta para inclusão de respondentes. Todos os que voluntariamente desejarem participar da pesquisa serão incluídos.

Todos os respondentes, bem como a escola, assinaram um Termo de Consentimento Livre e Esclarecido (TCLE), garantindo privacidade e sigilo de identidade, como sugere os critérios éticos de pesquisas com seres humanos.

A tabela abaixo explicita quem e quantos são os voluntários respondentes:

TABELA 1. Descrição dos Respondentes da Pesquisa em cada Escola Abordada.

\begin{tabular}{lcccccc}
\hline \multirow{2}{*}{ Escolas } & \multicolumn{2}{c}{ Universo dos Professores } & \multicolumn{2}{c}{ Universo dos Alunos } & \multicolumn{2}{c}{$\begin{array}{c}\text { Universo dos Técnicos } \\
\text { Administrativos }\end{array}$} \\
\cline { 2 - 7 } & Total & Respondentes & Total & Respondentes & Total & Respondentes \\
\hline Escola Pública & 16 & 16 & 25 & 25 & 4 & 4 \\
Escola Particular & 16 & 16 & 15 & 15 & 4 & 4 \\
\hline Total & 32 & 32 & 40 & 40 & 8 & 8 \\
\hline
\end{tabular}

FONTE: Dados da Pesquisa (2017).

Após definir a caracterização do local e dos respondentes da pesquisa, faz-se necessário descrever como se deu a coleta de dados. Segue abaixo a descrição.

\section{Coleta e Reflexão de Dados}

Segundo os critérios éticos de pesquisas com serem humanos, toda a coleta de dados deve ser realizada mediante voluntariado dos respondentes, garantindo a estes, sigilo de informações e identidade. Para garantir os direitos dos respondestes e deixá-los mais confortáveis com a realização da pesquisa, toda a coleta de dados ocorreu nas escolas descriminadas acima, em horários previamente agendados com a direção das escolas.

Como para este trabalho há três grupos de respondentes que percebem a inclusão escolar de formas distintas, a coleta de dados buscou adequação para cada público, ao mesmo tempo em que toda a extensão da coleta de dados, por mais que utilize recursos diferentes, deve ser complementado aos objetivos da pesquisa.

Guiando pela metodologia qualitativa, define-se que as análises e reflexões sobre os dados coletados serão feitos através da técnica de análise de conteúdo, que consiste na busca pela compreensão do fenômeno através da reflexão debruçada sob os relatos dos sujeitos da pesquisa, buscando categorizar as falas coletadas em grupos e subgrupos que componham os objetivos determinados (FRANCO, 2012). 
Sendo assim, segue abaixo a tabela de descrição da coleta e reflexão de dados.

TABELA 2. Descrição da Coleta de Reflexão dos Dados

\begin{tabular}{|c|c|c|c|}
\hline Respondentes & Objetivo & $\begin{array}{l}\text { Instrumento de Coleta de } \\
\text { Dados }\end{array}$ & $\begin{array}{c}\text { Categoria } \\
\text { de Análise e } \\
\text { Reflexão dos } \\
\text { Dados }\end{array}$ \\
\hline Alunos & $\begin{array}{l}\text { Identificar, a partir da ótica dos alunos, as } \\
\text { ações e características que para eles são } \\
\text { fatores de inclusão ou exclusão em um grupo, } \\
\text { comparando o contexto de uma escola pública } \\
\text { e de uma escola privada localizadas nas } \\
\text { cidades de Lavras/MG e Perdões/MG. }\end{array}$ & $\begin{array}{l}\text { Grupo Focal com } \\
\text { Registro em Diário de } \\
\text { Campo. Serão feitas } \\
\text { dinâmicas com foco na } \\
\text { temática 'relacionamento } \\
\text { interpessoal'. }\end{array}$ & \\
\hline Professores & $\begin{array}{l}\text { Averiguar, a partir da ótica dos professores, } \\
\text { quais são as demandas para inclusão escolar, } \\
\text { comparando o contexto de uma escola pública } \\
\text { e de uma escola privada localizadas nas } \\
\text { cidades de Lavras/MG e Perdões/MG. }\end{array}$ & Questionário semiaberto. & \\
\hline $\begin{array}{l}\text { Técnicos } \\
\text { Administrativos }\end{array}$ & $\begin{array}{l}\text { Compreender, a partir da gestão da escola, } \\
\text { quais são as ações e estratégias utilizadas e } \\
\text { exigidas para promover a inclusão escolar, } \\
\text { comparando o contexto de uma escola pública } \\
\text { e de uma escola privada localizadas nas } \\
\text { cidades de Lavras/MG e Perdões/MG. }\end{array}$ & Questionário semiaberto. & \\
\hline
\end{tabular}

FONTE: Dados da Pesquisa (2017).

O mecanismo para coleta de dados foi um questionário semiaberto para 16 (dezesseis) professores e 4 (quatro) membros do departamento administrativo das escolas e uma dinâmica no Ensino Fundamental Anos Finais, de uma turma de 6으 ano, em ambas as escolas. A dinâmica será feita durante a aula de Educação Física, e seguirá em dois momentos. O primeiro momento, os alunos serão comunicados sobre a finalidade da pesquisa e convidar os alunos para participar.

No segundo momento, dar início a dinâmica. Será distribuído balões de diferentes cores para cada um dos alunos, de forma que cada um escolherá a cor que mais gostar. Após a distribuição, será pedido que eles encham os balões por um tempo de 10 segundos.

Então, eles irão amarrar os balões e colocá-los no chão de forma a espalhá-los e de modo que não estoure. Assim sendo, os pesquisadores pedirão para que eles olhem em direção aos balões, que estão no chão e examinem o que reputaram de suas visões. Depois de analisar o que cada aluno opinou, os pesquisadores esclarecem a finalidade da dinâmica, que é sobre a relação interpessoal.

Os balões constituem a sociedade, as cores, dimensões e moldes que os balões ficaram depois de enchidos, representam as desigualdades de cada ser humano. Mesmo com as diferenças, eles continuam com a mesma natureza, ainda são "balões" e requerem respeito da mesma forma do balão que eles escolheram pela cor e pela forma como eles encheram.

Depois do esclarecimento dos pesquisadores, os alunos terão a chance de falar e ouvir quem já passou por situações de indiferença e registrar. Logo após a dinâmica, os pesquisadores vão explicar sobre a temática e averiguar se há casos nas escolas, caso haja, fazer registro. 
A aplicação do questionário será feita logo após a aceitação dos respondentes aos critérios éticos que serão entregues antes do início da pesquisa, esses critérios assegurarão os respondentes de sigilo a suas informações, protegendo sua imagem, nome e qualquer tipo de informação pessoal.

Segue abaixo um modelo do questionário aplicado para professores e auxiliares administrativos:

TABELA 3. Questionário aplicado na pesquisa

\section{1) Dados Sociodemográficos}

Idade:

Cargo:

Tempo Atuante na Referida Escola:

Tempo Atuante no Cargo Atual:

Escolaridade:

2) Para você, o que é uma demanda para a inclusão no contexto escolar?

A. ( ) Aluno com deficiência física.

B. ( ) Aluno com deficiência mental.

C. () Outros

- Por favor, comente sua resposta:

3) Para você, qual é o maior desafio na inclusão no contexto escolar?

A. ( ) Pouco ou nenhum recurso educacional.

B. ( ) Pouco ou nenhum apoio da supervisão escolar.

C. () Pouco ou nenhum apoio familiar dos alunos envolvidos no processo de inclusão.

D. ( ) Pouco ou nenhuma capacitação/conhecimento sobre o que é inclusão escolar.

E. ( ) Outros

- Por favor, comente sua resposta:

4) Qual é o seu papel no processo de inclusão escolar?
A. ( ) Mediar conflitos.
B. ( ) Intervir nos conflitos.
C. () Propor ações de melhoria.
D. ( ) Outros.
- Por favor, comente sua resposta:
5) Defina com suas palavras: o que é inclusão escolar?
- Por favor, comente sua resposta:

FONTE: Dados da pesquisa (2017).

\section{Análise dos Dados}

O estudo dos dados foi efetuado a partir da proposta de uma investigação descritivo-reflexiva que pode auxiliar uma melhor percepção e apuração dos fatos do registrados, e nos encaminhar a uma reflexão sobre sua causa. A partir disso pode-se caminhar adiante e direcionar uma explicação ao acontecimento (GRAHAM, 2009).

Depois de aplicado o questionário (tabela 3), fizemos uma investigação descritiva de cada questão proposta para cada uma das amostras, separadas por cargos. 


\section{Análises dos questionários}

\section{QUESTÃO 02: Para você, o que é uma demanda para a inclusão no contexto escolar?}

Em relação aos professores da rede pública, dos 16 (dezesseis) professores que responderam ao questionário, 06 (seis) responderam ( $\mathrm{a}$ e b), que a demanda para a inclusão no contexto escolar é de alunos com deficiência física e intelectual. Para 04 (quatro) professores destes 06 (seis), falaram que "a inclusão deve atender estes alunos é necessário um planejamento educacional adaptado também ter uma adaptação na estrutura física da escola", para 01(um) professor dependendo do grau deficiência intelectual do aluno ele não terá condições de estar incluso na escola, já para o outro optou por não comentar sua resposta. Ainda referente a esta questão 06 (seis) optaram pela alternativa (c) outros, dos 06, 04 mostram que a inclusão pode ser de alunos de vários tipos de necessidades especiais, mas que todos devem estar incluso na escola e os professores têm que buscar sempre o melhor para eles. 01 falou que "Inclusão é o privilégio de conviver com as diferenças sejam elas quais forem" e o outro falou que inclusão é para qualquer aluno que tenha dificuldades psicopedagógicas. Somente um professor respondeu todas as alternativas desta questão e comentou que a demanda vinda de pessoas com necessidades educacionais especiais.

Dos 16 (dezesseis) professores da rede privada, 15 (quinze) responderam que a demanda para a inclusão no contexto escolar seria a opção (c) outros, seria "algum tipo de deficiência constatada por médicos", "A inclusão no contexto escolar diz respeito a uma multiplicidade de características humanas que erroneamente são desqualificados, tais como cultura, etnia, religião, sexualidade, etc". Já o outro professor colocou a alternativa (a e b), que a demanda é para alunos com deficiência física e mental.

De acordo com Lacerda (2003), alunos com distúrbios comportamentais, déficits cognitivos diferenciados ou outros tipos de necessidades especiais vão ser atendidos de acordo com cada necessidade e serão considerados alunos especiais.

Em relação aos técnicos administrativos da rede pública, das 04 (quatro) amostras, 01(um) respondeu a alternativa ( $a$ e b) e justificou sua resposta da seguinte forma"

"Colocar estes alunos juntos com outros, para que tenham assim uma socialização". Para os outros 03 (três), a resposta foi à alternativa (c) que qualquer deficiência, seja ela física, mental ou motora.

Para os técnicos administrativos da rede privada, dos 04 (quatro) respondentes 01 (um) marcou a alternativa (a) que a demanda para a inclusão no contexto escolar é de aluno com deficiência física. 02 (dois) técnicos responderam as alternativas ( $a$ e b) que seria a deficiência física e mental e um comentou o seguinte "É acolher todos os alunos que chegam à escola, independentemente de sua condição". E por fim o outro marcou a alternativa (c) outros, alegando que a "dificuldade de aprendizagem dos alunos, níveis diferentes".

\section{QUESTÃO 03: Para você, qual é o maior desafio na inclusão no contexto escolar?}

Em relação aos professores da rede pública, dos 16 (dezesseis), 03 (três) marcaram a alternativa (a) falando que o maior desafio na inclusão no contexto escolar é pouco ou nenhum recurso educacional, 02 (dois) deles comentaram que ainda precisa melhorar quanto aos recursos, mas que ainda assim tem a inclusão. 01 (um) professor comenta que "Na presente escola é oferecido sala, recursos e professores apoio, mas não é a realidade da maioria das outras escolas onde lecionei que o aluno que necessita da inclusão apenas estuda na escola regular, onde são oferecidas poucas propostas da inclusão". 
01 (um) professor marcou a alternativa (a e c) que o maior desafio além do recurso educacional tem também o pouco apoio da família. 02 (dois) professores responderam a alternativa (a e d) que junto com o pouco recurso escolar tem também pouca capacitação da escola. 01(um) respondeu a alternativa ( $a, c$ e d) pouco recurso, pouco apoio familiar e pouca capacitação e comentou o seguinte "Para que a educação inclusiva se torne realidade é preciso que todos os sistemas educacionais oportunizem cursos de formação aos seus educadores". 03 (três) professores marcaram a alternativa (d) que seria a pouca capacitação/conhecimento. Os outros 03 (três) professores responderam a alternativa (e) outros, e um comentou o seguinte "Hoje contamos com cursos e recursos que vem contribuindo apara atender alunos com necessidades educacionais adaptadas, mas para isto, o profissional tem que ter o conhecimento e amor para isto".

Já na rede privada dos 16 (dezesseis) professores respondentes, 03 (três) responderam a alternativa (a) que o maior desafio na inclusão seria pouco ou nenhum recurso educacional e um professor citou o seguinte "Muitas vezes as escolas não estão adaptadas para receber alunos com necessidades especiais".

01(um) professor marcou as alternativas (a e d), mas não comentou nada sobre a questão marcada. 01 (um) outro professor falou que o maior desafio seria pouco ou nenhum apoio da supervisão escolar, que seria a alternativa (b). 03 (três) professores falaram que a alternativa (c) seria a maior dificuldade, pouco ou nenhum apoio familiar dos alunos envolvidos no processo de inclusão e um deles comentou o seguinte "Deve haver uma parceria entre a escola e família para o bom desenvolvimento da criança".

03 (três) professores marcaram a alternativa (d) que a maior dificuldade seria, pouca ou nenhuma capacitação/conhecimento sobre o que é inclusão escolar, e um deles comentou que "Ainda existe muitas linhas de pensamento e poucas atitudes construtivas e eficientes nesta questão". Os 05 (cinco) professores que marcaram a alternativa (e)-outros, falaram o seguinte "Vários fatores envolvem uma inclusão escolar, pois nela deve estar envolvida: escola, comunidade e família", "A política inclusiva exige não só a capacitação de profissionais, mas, a viabilização desta logística, principalmente na rede particular".

Para Lacerda (2003) O foco de início é incluir o aluno em salas de aulas do ensino regular, contando com a ajuda de todos, os pais e comunidades tem que estar nesse meio. Isso faz com que a sociedade pense sobre as circunstâncias em que os alunos se encontram e quais as alterações necessárias para que eles possam ser presentes na sociedade em que vive.

Na rede pública, contamos com 04 (quatro) técnicos administrativos, destes 04, 01(um) respondeu a alternativa (a) falando que eles precisam de ajuda como psicólogos, orientadores e pedagogos. 01(um) somente marcou a alternativa $(a, d)$, mas não justificou sua resposta. Os outros 02 (dois) restantes marcaram a opção (e) outros, e um comentou o seguinte "Situação política/financeira e social do Brasil, que não alega direitos reais para a escola exercer a inclusão.

Dos 04 (quatro) técnicos respondentes da rede privada, 01(um) marcou a alternativa (a) pouco ou nenhum recurso educacional e falou o seguinte "Nesse contexto a escola não se constitui de maneira diferente. Não está preparada para receber estes alunos". Outro técnico marcou a alternativa (c), porque para ele o maior desafio seria pouco ou nenhum apoio familiar dos alunos envolvidos no processo de inclusão, mas não comentou nada a respeito dessa questão. Os outros 02 (dois) técnicos marcaram a alternativa (e) - outros e comentaram o seguinte "Falta de conhecimento do problema apresentado pelo aluno e de como tratá-lo. 
Preconceito da comunidade escolar, principalmente dos pais. Aceitação da família". "É muito difícil vencer o preconceito".

Segundo Santos e Martinez (2016), alguns indicadores mostram aspectos negativos quanto aos desafios dos profissionais das escolas, que seriam: Falta de conhecimento dos profissionais das escolas quanto à política da educação inclusiva e ausência das normas de acessibilidade, tanto os professores quanto os gestores da escola se manifestam com respeito nos encontros de formação, mas não ficaram de forma ativa nas atividades planejadas.

\section{QUESTÃO 04: Qual é o seu papel no processo de inclusão escolar?}

Em relação aos professores da rede pública, dos 16 (dezesseis) participantes, 02 (dois) responderam à alternativa (a), que seu papel no processo de inclusão seria de mediar conflitos. 02 (dois) professores responderam que seu papel seria mediar conflitos, intervir nos conflitos e propor ações de melhoria, marcando assim a alternativa ( $a$, b e c). Outro professor marcou a alternativa (a e c), falando que seu papel seria de mediar conflitos e propor ações de melhoria. Um professor disse que seu papel seria de intervir e propor melhoria e concluiu o seguinte "Nós tentamos incluir estes alunos no contexto geral das aulas". 08 (oito) professores marcaram a alternativa (c), dizendo que seu papel é de propor melhorias, e um citou o seguinte "Adaptar as atividades, respeitando as individualidades de cada aluno". Por último, 03 (três) professores marcaram a alternativa (d) falando que "o papel do professor de apoio na inclusão escolar é um agente medidor nos processos de desenvolvimento e aprendizagem e parceria com $o$ professor regente".

Em relação aos professores da rede privada, dos 16 professores respondentes, 01 (um) professor marcou a alternativa ( $a, b$ e c), que seu papel na inclusão escolar seria de mediar conflitos, intervir nos conflitos e propor ações de melhoria.11(onze) professores marcaram a alternativa (c) que seu papel seria de propor ações de melhoria, e algum deles comentaram o seguinte "O professor conhecendo a realidade escolar pode e deve propor melhoria neste conceito", "Buscar formas de adequar a inclusão da melhor maneira, não só na escola, mas também na sociedade". Os 04 (quatro) últimos professores marcaram a alternativa (d) - outros e dois alegaram o seguinte "Receber, apoiar, buscar melhoria, buscar conhecimento para melhor atender o aluno especial", "Buscar, constantemente meios para vencer o preconceito".

A regularização tem como proposta, tornar alcançável as pessoas que por meio da sociedade não são valorizadas, e fazer com que seu estilo de vida fica semelhantes as outras pessoas que estão inseridas na sociedade. Assim, imagina-se a aceitação de um novo padrão de assistência entre os seres humanos, introduzindo ações que visam a inteirar toda forma de rotulação (LACERDA, 2003).

Na rede pública entrevistamos 04 (quatro) técnicos administrativos, um respondeu a alternativa ( $a, b$ e c) que seu papel é de mediar conflitos, intervir nos conflitos e propor ações de melhoria. Os outros 03 (três) responderam a alternativa (c)propor ações de melhorias e ainda concluiu o seguinte "Com os poucos recursos que nos oferecem precisamos ajudar a direção dando ideias para melhorar esses atendimentos".

Na rede privada entrevistamos 04 (quatro) técnicos administrativos, 01 (um) deles marcou a alternativa ( $a$, b e c) que seu papel na inclusão escolar seria de mediar conflitos, intervir nos conflitos e propor ações de melhoria. 02 (dois) responderam a alternativa (c) que o seu papel seria de propor ações de melhoria. O último marcou a alternativa (d)-outros e comentou o seguinte "Tem que buscar meios para vencer os preconceitos". 


\section{QUESTÃO 05: Defina com suas palavras: o que é inclusão escolar?}

De acordo com os professores da rede pública, dos 16 respondentes, 09 (nove) tiveram a mesma perspectiva do que é a inclusão escolar a inclusão escolar para eles é "Fazer com que todos fazem parte de um todo onde as diferenças desapareçam e todos possam sentir-se bem por estar naquele grupo".

02 (dois) professores acham que a inclusão escolar pode ser definida como: "São capacitações curriculares, para atender alunos que necessitam destas adaptações para a sua inserção nas escolas".

Para 02 (dois) professores a inclusão seria "Criar o sentimento de pertencimento e importância no meio em que vive, recebendo conhecimento de acordo com suas limitações".

Para os técnicos da rede pública, 02 (dois) falaram que a inclusão escolar seria "É conviver com todos sem exceção, independente, condições, cor, sexo e classe social".

Para 01(um) a inclusão escolar é "Tentativa de amenizar a exclusão social que afeta o indivíduo que possui qualquer tipo de deficiência".

Para o outro técnico a inclusão escolar é "Ter apoio do governo dando formações para os profissionais que estão trabalhando juntos destes alunos".

De acordo com os 16 (dezesseis) professores da rede privada, para 06 (seis) a inclusão escolar seria algo relacionado com a socialização do aluno no meio em que vive "Assegurar que os alunos em toda sua diversidade, sejam tratados e reconhecidos sem nenhum tipo de discriminação, como cidadão com direito a educação", "Trazer todo tipo de ser humano para um convívio social com direitos e deveres iguais".

Para 01 (um) professor a inclusão estaria relacionada também com a comunidade em que o aluno vive "Inclusão escolar é o atendimento pedagógico e social aos alunos com ou sem deficiência, tanto na escola quanto na comunidade".

Para 07 (sete) professores, a inclusão seria um conjunto de possibilidades no meio escolar "A escola oferecer um ambiente onde a criança possa desenvolver suas habilidades dentro de suas limitações", "Inclusão escolar é o conjunto de ações que possibilite a participação "igualitária" do indivíduo no meio escolar".

Para 01(um) professor a inclusão escolar seria uma oportunidade para o aluno com necessidades especiais. E um outro, professor não se manifestou a respeito desta questão.

A assimilação dos professores aparentou estar associado à inclusão como um símbolo de justiça social, um apoio as pessoas que evidenciam diversidades e carecem de uma orientação e não as propostas pedagógicas reunidas na inclusão dos alunos, cujos propósitos estão direcionados para a continuidade dos mesmos nas escolas regulares (LACERDA, 2003).

De acordo com os 04 (quatro) técnicos administrativos da rede privada, 03 (três) responderam que a inclusão escolar seria "Acolher e dar condições ao aluno que apresenta algum problema, seja físico, intelectual e de aprendizagem e fazê-lo adquirir conhecimentos e ser autônomo" "Acolher todas as pessoas, sem exceção, no sistema de ensino, independente de cor, classe social e condições físicas e psicológicas" e por último "Inclusão escolar é o acolhimento de todas as pessoas, sem exceção, no sistema de ensino. É o acesso escolar igualitário sem discriminação". E para o último respondente seria "Ensino de qualidade, de acordo com a necessidade de cada educando". 


\section{Análise da dinâmica com os alunos}

Na escola privada o número da amostra foi de 15 alunos, já na escola da rede pública esse número foi maior, de 25 alunos participantes. A dinâmica aconteceu na aula de Educação Física, seguindo as propostas e intencionalidades de sensibilizar a todos quanto à importância da abordagem temática de identificar as diferenças e promover sentimentos de inclusão.

Consideramos que a realização desta dinâmica com os alunos foi de suma importância, pois ao participarem dela, os alunos e alunas demonstraram interesse enorme sobre o assunto, e estarem abertos a melhor conviver com as diferenças, sempre pautados com respeito e solidariedade, o que demonstraram nos e exemplos que puderam compartilhar no momento de conversas, logo após as reflexões da dinâmica. Também deixaram claro que maioria já teve contato com alunos com alguma necessidade especial, e que esse fato para eles não fazia diferença.

Com base na interpretação da realidade percebida, percebemos que por parte dos alunos e alunas, não há resistência em conviver com a diferença, mas que essa realidade deve ser conduzida por ações educativas e pedagógicas que conduzam uma boa qualidade do convívio social proposto pela escola, pautado no princípio da igualdade.

\section{Uma breve conclusão que não se finda...}

Nota-se com a realização destes estudos comparativos e com a contextualização e interpretação da realidade experimentada, que há dificuldade de se compreender e de lidar o que vem a ser uma demanda inclusiva nas escolas.

Mas também há caminhos possíveis que a educação pode tomar para que os sujeitos sociais atores - da escola, seja na rede privada ou na rede pública de ensino, possam possibilitar transformações em seu contexto de atendimento educacional de forma inclusiva e para todos.

Isso indica que tem que haver mais interesse da parte destes atores da escola em saber mais sobre o assunto, em se buscar mais possibilidades de mudanças e adaptações, para que assim seu atendimento especializado possa fazer a diferença na vida de seus alunos que precisam ser incluídos, seja socialmente, afetivamente, psicologicamente e cognitivamente. Se esse entendimento se dinamizar, o assunto em questão se transformará em algo positivo e concreto para todos da escola e sociedade.

\section{Referências}

AGUIAR, J. S. de; DUARTE. A. "Inclusive education: a study in the physical education field." Revista Brasileira de Educação Especial 11.2. 2005: 223-240.

ALVES, M. L. T.; DUARTE, E. A percepção dos alunos com deficiência sobre a sua inclusão nas aulas de Educação Física escolar: um estudo de caso. Rev Bras Educ Fís Esporte, (São Paulo) 2014 Abr-Jun; 28(2):329-38.

ANJOS, H. P. dos,; ANDRADE, E. P. de, PEREIRA, M. R. A inclusão escolar do ponto de vista dos professores: o processo de constituição de um discurso. Revista Brasileira de Educação v. 14 n. 40 jan./abr. 2009. 
BENITEZ, P.; DOMENICONI, C. Inclusão Escolar: O Papel dos Agentes Educacionais Brasileiros. Psicologia: ciência e profissão, 2015, 35(4), 1007-1023.

BIAVATTI, M. M. Z. S.; O profissional de educação física frente ao processo de inclusão escolar. Porto Velho - RO 2012.

BULGACOV, S. Estudos comparativos e de caso de organizações estratégicas. Revista Organizações e Sociedades. Vol. 5. No 11. Janeiro/Abril 1998. Disponível em: https://portalseer.ufba.br/ index.php/revistaoes/article/view/10375/7394 Acesso em: Outubro 2019.

COSTA, V. B. da. Inclusão escolar na educação física: reflexões acerca da formação docente. Motriz, Rio Claro, v.16, n.4, p.889-899, out./dez. 2010890.

FRANCO, M. L. P. B. Análise de Conteúdo. Editora Liber Livro. Vol. 6. 2012. 96 págs.

GOMES, C.; REY, F. L. G. Inclusão Escolar: representações compartilhadas de profissionais da educação acerca da inclusão escolar. Psicologia Ciência Profissão, 2007.

GRAHAM, G. Análise de dados qualitativos. Porto Alegre: Artmed, 2009.

KIBRIT, B. Possibilidades e desafios na inclusão escolar. Rev. Latinoam. Psicopat. Fund., São Paulo, 16(4), 683-695, dez. 2013.

LACERDA, D. H de. Educação Inclusiva, cotidiano escolar e as concepções e práticas de professores. Uberaba, 2003.

LAPLANE, A. L. F. de. Condições para o ingresso e permanência de alunos com deficiência na escola. Cad. Cedes, Campinas, v. 34, n. 93, p. 191-205, maio-ago. 2014.

MANTOAN, M. T. E. A Integração de pessoas com deficiência: contribuições para uma reflexão sobre o tema. São Paulo: Memnon, 2004.

Educação Especial na Perspectiva Inclusiva: o Que Dizem os Professores, Dirigentes e Pais. Revista Diálogos e Perspectivas em Educação Especial, v.2, n.1, p. 23-42, Jan. Jun., 2015.

Inclusão Escolar: o que é? por quê? como fazer? Summus Editorial, 2015.

MATURANA, A. P. P. M.; CIA, F. Educação Especial e a Relação Família - Escola: Análise da produção científica de teses e dissertações. Revista Quadrimestral da Associação Brasileira de Psicologia Escolar e Educacional, SP. Volume 19, Número 2, Maio/Agosto de 2015: 349-358.

MENDES, E. G. A radicalização do debate sobre inclusão escolar no Brasil. Revista Brasileira de Educação. 2006.

MENDONÇA, F. L. de R; SILVA, D. N. H. A formação docente no contexto da inclusão: para uma nova metodologia. Cadernos de Pesquisa v.45 n.157 p.508-526 jul./set. 2015.

NACIF, M. F. P.; et al. Educação Física Escolar: Percepções do Aluno com Deficiência. Rev. Bras. Ed. Esp., Marília, v. 22, n. 1, p. 111-124, Jan. Mar, 2016. 
PAGNI, P. A. Diferença, subjetivação e educação: um olhar outro sobre a inclusão escolar. Pro-Posições | v. 26, n. 1 (76) | p. 87-103 | jan./abr. 2015.

RAMPAZZO, L. Metodologia Científica para Alunos dos cursos de Graduação e Pós-Graduação. São Paulo. Edições Loyola. 3ạ edição. 2005.

REIS, K. S. dos. A inclusão escolar de alunos com necessidades educacionais especiais: uma análise das falas de educadores. São Paulo. 2011.

RESENDE, C. D. A inclusão escolar na ótica dos professores de ensino fundamental da rede municipal de Criciúma. Criciúma. 2010.

ROSIN-PINOLA, A. R; DEL PRETTE, Z. A. P. Inclusão escolar, formação de professores e a assessoria baseada em habilidades sociais educativas. Rev. Bras. Ed. Esp., Marília, v. 20, n. 3, p. 341-356, Jul.-Set., 2014.

RUIZ, M. C. A inclusão de portadores de necessidades especiais nas aulas de educação física. Rondônia. 2008.

SANTOS, G. C. S.; MARTÍNEZ, A. M. A subjetividade social da escola e os desafios da inclusão de alunos com desenvolvimento atípico. Rev. Bras. Ed. Esp., Marília, v. 22, n. 2, p. 253-268, Abr. Jun., 2016

SILVA, M. O. E. da. Da exclusão à inclusão: concepções e práticas. Revista lusófona de educação. 2009. 